\title{
Marca, imagem, signo: uma abordagem semiótica de Espinoza ${ }^{1}$
}

Lorenzo Vinciguerra

Resumo: Ao invés de ler a teoria da imaginação de Espinoza de maneira antropocêntrica, como dependente da doutrina tradicional das faculdades humanas, o autor a considera como uma consequência de sua física e de sua cosmologia. O conhecimento por signos, como Espinoza chama a imaginação, deve estar enraizado em sua teoria das marcas e imagens, e diz respeito a todos os seres (humanos e não humanos) que são capazes de marcar outros corpos e de serem marcados por eles numa semiose infinita da natureza.

Palavras-chave: semiótica de Espinoza; teoria dos signos; imaginação; marca; imagem.

Abstract: Instead of reading Spinoza's account of the imagination in an anthropocentric way, as dependent on the traditional doctrine of human faculties, the author considers it as a consequence of its physics and its cosmology. The knowledge by signs, as Spinoza calls imagination, has to be rooted in his theory of marks and images, and concerns all beings (human and non-human) who are able to mark other bodies and to be marked by them in infinite semiosis of nature.

Keywords: Espinoza's semiotics; theory of signs; imagination; mark; image.

Não é usual falar de semiótica em Espinoza. O termo semiótica não aparece em seu trabalho e foi introduzido por Locke, apenas alguns anos após sua morte. Entretanto, o signo já vinha sendo tema de debate na filosofia durante o século XVII. Encontramos valiosas observações sobre esse tópico na lógica de Port-Royal e nos textos de Hobbes, por exemplo, e, subsequentemente, em Locke, Berkeley, Condillac e Vico. Em Espinoza, a reflexão sobre o signo está longe de ser periférica. Quem estiver familiarizado com os primeiros capítulos do Tractatus Theologico-Politicus reconhecerá que uma de suas

1 Versão de "Mark, Image, Sign: a semiotic approach to Spinoza". Artigo publicado originalmente em European Journal of Philosophy, 20:1, pp. 130-144. Blackwell Publishing: Oxford UK, 2012. 
maiores contribuições ao pensamento ocidental, nomeadamente, separar a filosofia da teologia pela distinção entre a filosofia e a revelação profética, depende do signo. Além disso, o signo está, por sua vez, entrelaçado com a oposição entre intelecto e imaginação que atravessa todo o pensamento de Espinoza. Na Ética, Espinoza descreve a imaginatio como cognitio ex signis; o signo também assume um papel central no Tractatus de Intellectus Emendatione (ao referir-se à teoria da verdade e da certeza); e o mesmo ocorre em Korte Verhandeling (ao referir-se à revelação divina). A importância da reflexão de Espinoza sobre a natureza dos signos, a forma como são atualizados e sua maneira de conduzir o sentido é, em geral, reconhecida. Mesmo assim, ainda resta compreender a lógica interna de sua discussão sobre o signo.

O problema do signo, em alguma medida, remete à origem da própria filosofia. Platão deu início a uma longa história ao ligar o sema ao soma, atando o destino do signo à filosofia do corpo e da escrita e criando, assim, uma dualidade entre corpo e alma. A lógica aristotélica forneceu uma sistematização duradoura do problema com a teoria do silogismo e a doutrina da substância e acidentes, à qual os Estoicos opuseram a lógica dos acontecimentos construída a partir de inferências, elas próprias baseadas em signos. Os problemas do sentido e da linguagem, incluindo a essência e o destino dos seres humanos em suas relações com os deuses e a natureza, estão todos encerrados na ambiguidade e versatilidade do signo.

A assim chamada virada linguística e semiótica da segunda metade do século XX indicou que a reflexão acerca do signo nunca abandonou o pensamento ocidental. A história desse tema talvez seja aquela de um deus menor quando comparada às mais nobres histórias da metafísica. Mesmo assim, ela tem questionado os pressupostos essencialista e substancialista da tradição ocidental e, em larga medida, resta a ser escrita. Por um longo tempo, Espinoza foi marginalizado em ambas essas histórias, removido das principais correntes da metafísica e quase esquecido na história da semiótica. Talvez, como pensou Hegel, na esteira de Bayle, ele fosse muito oriental para ser assimilado sem danos à tradição bíblica teológica. Paradoxalmente, ele seria também demasiadamente cartesiano, pelo menos à primeira vista, para ser considerado como alguém que tivesse oferecido uma contribuição original à história da representação. ${ }^{2}$

Para fazer eco à expressão introduzida por Toni Negri, a ausência de Espinoza nos estudos semióticos constitui uma espécie de anomalia. Isso serve como um convite a interrogar uma obra que resiste aos padrões estabelecidos de nossa tradição e permite o crescimento de uma certa desconfiança. Diante disso, seria insensato assumir que a ontologia de Espinoza, tão heterodoxa no contexto do racionalismo moderno, não teria deixado marcas em sua teoria da imaginação. Entender a filosofia de Espinoza é, em parte, refletir sobre a maneira como nos acostumamos a ler seus textos, e ponderar acerca da nossa tendência natural a projetar sobre sua obra, inconscientemente, sentidos específicos

2 Com algumas exceções interessantes: MIGNINI, 1981; FABBRI, 1998; SINI, 2005. 
e hábitos de pensamento que ele pretendeu reformar. Enfatiza-se, frequentemente, que o vocabulário da Ética é tudo menos original. Espinoza adotou a terminologia escolástica e cartesiana corrente em sua época. Contudo, os sentidos de seus termos desviam-se da tradição, às vezes radicalmente.

A teoria de Platão sobre as faculdades da alma e sua dicotomia com o corpo, seguida pela tradição agostiniana e renovada por Descartes, moldou muito da nossa epistemologia e antropologia. Espinoza criticou essa visão com a intenção de reformá-la. Entretanto, essa tradição ainda exerce uma profunda influência no modo como pensamos, e persiste como um obstáculo epistemológico a uma melhor avaliação do espinozismo. Esse problema é particularmente agudo em relação ao que entendemos sobre o que Espinoza chama de imaginação ou de primeiro gênero do conhecimento. Aqui, encontramos um tipo de conhecimento que resiste a ser lido como uma variante da doutrina da tripartição da alma, precisamente porque os princípios da ontologia platônica foram subvertidos por Espinoza. Na Ética, a teoria do conhecimento caminha de mãos dadas com a ontologia. A absoluta necessidade da substância única exclui a existência de qualquer outra substância no mundo. Há apenas atributos da substância única e seus modos.

Na Ética, como sabemos, os seres humanos são introduzidos somente na segunda parte do livro, com um teorema que era desconhecido nos tempos de Espinoza e largamente incompreendido: o ser humano não é uma substância. O leitor é, então, convocado para uma radical mudança de perspectiva. Pode-se mesmo dizer e repetir que o ser humano não é uma substância, mas continuando a pensar como se os humanos fossem seres substanciais, seguindo os ensinamentos que a tradição ocidental, desde Aristóteles, nos legou. Para Espinoza, entretanto, o ser humano é parte da natureza e não tem poder de autodeterminação, seja mental ou física. O corpo humano não é um indivíduo independente. Como qualquer outro corpo na natureza, não está totalmente separado de outros corpos individuais e precisa, constantemente, do suporte deles, da mesma forma que a mente humana precisa de outras mentes para desenvolver seu próprio pensamento. Em outras palavras, a mente humana não é a fonte de suas próprias ideias. Sendo em si mesma uma ideia, ela é causada por outras ideias. Portanto, como um modo corpóreo e mental, o ser humano só existe como um ser em relação com outras coisas, as quais o afetam e são afetadas por ele.

Num dos teoremas mais importantes da primeira parte da Ética (2009, I p16, p. 26), ${ }^{3}$ Espinoza anuncia que "da necessidade da natureza divina devem se seguir infinitas coisas, de infinitas maneiras (isto é, tudo o que pode ser abrangido sob um intelecto divino)"

3 Todas as traduções têm como fonte: The Collected Works of Spinoza vol. 1, ed. And, trans. Edwin Curley, Princeton: Princeton University Press, 1985. Para a tradução no português: ESPINOZA, Ética. Tradução de Tomaz Tadeu. Ed. Autêntica: Belo Horizonte, 2009. Entre os especialistas em Espinoza, é consensual, ao comentarem a Ética, citarem, por exemplo, a proposição 16 da Parte I, da seguinte forma: (I p16); caso refiram-se ao corolário da mesma proposição: (I p16c), em razão do modo geométrico que constitui o livro, com axiomas, proposições, demonstrações, corolários, escólios etc. Para adequarmos essa forma de citação às regras usualmente adotadas em Galaxia, decidimos fazer uma pequena adaptação, indicando também a página do trecho referido: (I p16, p. 26). 
Como ele passa a explicar, os modos eternos e infinitos dos atributos que seguem da natureza divina são de duas espécies: o modo eterno infinito imediato, que se segue da natureza absoluta de algum atributo (ESPINOZA, 2009, I p21, p. 30), e o modo eterno infinito mediato, que se segue de algum atributo na medida em que sofre uma modificação que, por meio desse atributo, existe tanto necessariamente quanto como infinito (idem, I p22, p. 31). O movimento se segue imediatamente do atributo extensão como seu modo infinito imediato, assim como o intelecto infinito de Deus se segue do atributo pensamento. Quanto aos modos mediatos infinitos, que Espinoza descreve numa carta como a facies totius universi, eles se seguem de modificações no modo infinito da extensão. Já o que é concebido como mente infinita do universo - algo para o que Espinoza não atribuiu nenhum nome - se segue de modificações no modo infinito do pensamento (vide Tabela 1).

Sob a doutrina dos atributos, a demonstração da proposição 16 também implica que, da natureza do pensamento, infinitas ideias devem se seguir de infinitas maneiras (isto é, todas as ideias que podem se dar sob uma mente infinita). O mesmo pode ser dito sobre o atributo extensão: da natureza da extensão devem se seguir infinitos corpos de infinitas maneiras (isto é, todos os corpos que podem ser distinguidos pelo movimento). Os corpos dos seres humanos, com todas as suas peculiaridades, são apenas instâncias particulares de tais corpos. Como se mostrará, a epistemologia de Espinoza, tanto como sua antropologia, deve ser compreendida em sua estrutura ontológica e cosmológica, tal como exposto na primeira e segunda partes da Ética e, especialmente, na seção da Parte II dedicada à física.

Se levarmos essa perspectiva a sério, nem o intelecto (que é o mesmo em todas as mentes humanas), tampouco a imaginação (que é particular) podem ser considerados como características exclusivas das mentes e dos corpos humanos. Aquilo que entendemos, o fazemos como mentes e como parte do intelecto infinito de Deus: "portanto, quando dizemos que a mente humana percebe isto ou aquilo, não dizemos senão que Deus, não enquanto infinito, mas enquanto é explicado por meio da natureza da mente humana, ou seja, enquanto constitui a essência da mente humana, tem esta ou aquela ideia. E, quando dizemos que Deus tem esta ou aquela ideia, não enquanto ele constitui a natureza da mente humana apenas, mas enquanto tem, ao mesmo tempo que [a ideia que é] a mente humana, também a ideia de outra coisa, dizemos, então, que a mente humana percebe essa coisa parcialmente, ou seja, inadequadamente" (idem, II p11c, p. 59).

Quando a mente humana percebe nesse último sentido, é dito que ela imagina. Não há razão, em princípio (exceto talvez por um preconceito substancialista e antropocêntrico), de não se aplicar essa perspectiva lógica e cósmica a outros indivíduos, ao menos sob certas condições. Tudo o que as pessoas imaginam segue a ordem e as conexões de suas afecções corporais na medida em que seus corpos movem outros corpos e são movidos por eles. Em outras palavras, elas imaginam de acordo com as leis gerais com as quais todos os corpos estão em conformidade, e se relacionam entre si como partes de um indivíduo infinito que constitui o universo. 
Uma vez que não se pode dizer que um ser humano seja o subjectum substancial de seus pensamentos, mas sim o sujeito de pensamentos ou ideias que o atravessam, ele também não pode ser visto como o auctor exclusivo do que imagina. Deveríamos, antes, pensá-lo como um actor ou, como Espinoza apropriadamente coloca, um interpreter. Não temos o pensamento em nós, mas somos no pensamento como modos da substância pensante. Analogamente, nossos corpos são modos da extensão; na extensão, movemos outros corpos e somos movidos por eles, corpos que modificamos e pelos quais somos, simultaneamente, modificados. A res cogitans, ela mesma, pensa em nós, através de nós, assim como a res extensa, simultaneamente, modifica a si mesma em nossos corpos. De um modo geral, isso deve ser verdade para cada mente e indivíduo. Mas isso significa que, quando imaginamos, nossos pensamentos chegam, em parte, de fora; e aqui é onde entra a linguagem. Tornamo-nos corpos que falam porque somos afetados por outros corpos que falam, e Espinoza descreve todas essas affectiones, que sempre se referem a outros corpos, como images, figurae, signs.

Se os seres humanos são, por natureza, intérpretes de signos, isso não seria por força de uma suposta faculdade de suas almas, mas em virtude do fato de que eles expressam a essência de Deus por meio de um corpo que tem o poder de afetar e ser afetado, um poder compartilhado por todos os indivíduos. A imaginação não pertence apenas aos indivíduos humanos, mas a todos aqueles que, embora em diferentes proporções, estão propensos a se engajar no poder de afetar e ser afetado. A insistência de Espinoza no papel fundamental da interpretação não deve ser mal compreendida: não há aqui nenhum subjetivismo hermenêutico. Ao invés disso, ele nos oferece um realismo radical: o sentido é um produto da natureza envolvendo todas as mentes, elas próprias consideradas como ideias. O panteísmo de Espinoza tem sido reconhecido, frequentemente, com um panpsiquismo, mas precisaríamos considerar como seu panpsiquismo implica uma teoria particular do sentido.

\section{Uma definição genética da imaginação}

Não é um exagero dizer que, desde seus parágrafos iniciais, o Tractatus TheologicoPoliticus instala o leitor no que poderia ser chamado de o império do signo. O famoso Preface expõe como a superstição opera por meio do conceito de presságio (omen). O presságio é um signo, que pode ser encarado como um aviso se dá lugar ao medo, e que pode ser visto como favorável se dá origem à esperança. Espinoza já havia discutido os presságios numa carta dirigida a Peter Balling (Carta 17), e mesmo na Ética (III p50, p. 130). A esse respeito, o Tractatus Theologico-Politicus deve muito a seus outros trabalhos. Contudo, os capítulos I e II, dedicados à Profecia e ao Profeta, podem ser vistos como uma profunda reflexão sobre a natureza e função dos signos. O surgimento do signo é crucial para distinguir a profecia do conhecimento natural, bem como para distinguir o profeta 
do filósofo (propagator). Por isso, serve para definir um traço que distingue a filosofia da religião ou teologia.

Para definir com clareza essa separação, Espinoza utiliza no primeiro capítulo do Tractatus Theologico-Politicus, embora sem citá-la, uma passagem de um trabalho anterior. A passagem encontra-se no Tractatus de Intellectus Emendatione (seções 35-36), onde Espinoza afirma que a verdade não requer nenhum signo, nenhum critério externo, mas garante-se por si mesma: “a certeza não é nada senão a própria essência objetiva, isto é, o modo pelo qual sentimos a essência formal é a própria certeza" . ${ }^{4}$ De acordo com essa passagem, veritas se ipsam patefacit: a verdade se mostra ou se revela a si mesma, e nossa consciência da verdade depende da própria natureza de uma ideia. Fica bem clara aqui a superioridade da filosofia sobre a religião. Enquanto a religião opera com signos que devem ser interpretados, a filosofia aspira a uma verdade que não precisa de signo.

Deve-se ter em mente, no entanto, que o conhecimento derivado de ambas, a profecia e a filosofia, pode ser descrito corretamente como revelado. A revelação filosófica não precisa de signo para ser entendida como certa, ela precisa apenas da ideia de Deus, e essa é uma maneira pela qual, sobre Deus, pode ser dito revelar-se a si mesmo. Por outro lado, a revelação profética necessita de um signo, porque os profetas a recebem via imaginação. Como argumenta Espinoza, Deus revela-se a si mesmo aos profetas por meio de imagens e/ou palavras: omnia quae Deus prophetis revelavit, iis revelata fuerunt vel verbis vel figuris utroque hoc modo, verbis et figuris. No entanto, Espinoza também afirma que, para estar seguro da profecia, o profeta deve convocar outro signo que confirme o primeiro. Apenas por meio de um segundo signo o profeta pode alcançar a certeza moral (certitudo moralis) que confere a ele próprio e à profecia uma autoridade teológica e política. Como resultado, alguns comentadores falam de uma revelação-duplo-signo (LAUX, 1993, p. 33).

Além da questão de como os signos são destinados a operar, vale indagar o que exatamente Spinoza pode ter em mente quando se refere aos signos. Apenas alguns comentadores fizeram essa pergunta. Quando o fizeram, eles responderam, em geral, com o argumento apressado de que a expressão signo se referia às palavras da linguagem escrita ou falada. ${ }^{5}$ Mas talvez essa resposta, com base no fato de que Espinoza utiliza com frequência as palavras escritas ou faladas como exemplos de signos, seja muito rápida. ${ }^{6}$ As palavras podem ser bons exemplos de signos, claro, mas são apenas exemplos e não explicam a natureza do signo em si mesma. Esquecemos, muitas vezes, que Espinoza caracteriza o primeiro gênero do conhecimento (opinio, memoria, imaginatio) como um conhecimento constituído por signos: cognitio ex signis. Essa definição precisa de uma maior consideração. De acordo com Ética II p17s, a mente imagina quando considera ocorpo através de suas imagens. Mas o que seriam essas imagines rerum? Espinoza (2009, II p17s, p. 68)

\footnotetext{
4 Tractatus de Intellectus Emedatione, Seção 35.

5 Ver p.ex. CURLEY, 1973, p. 30; para outras interpretações, ver MIGNINI, 1981, p. 189-226; MOREAU, 1994, p. 307-78; LAUX, 1993, p. 13-88.

6 P.ex., na Ética (2009, II p40sll, p. 81).
} 
nos diz que elas são "as afecções do corpo humano, ideias que representam os corpos externos como presentes a nós, mesmo se elas não reproduzem as figuras das coisas".

Com base na Ética II p16c2, compreendemos que a imaginação indica a constituição do corpo que é afetado, mais do que a natureza do corpo externo que causa a afecção. De fato, Espinoza vai muito mais longe em sua explicação sobre a natureza das imagens. Ele nos fornece elementos para uma definição genética, oferecendo uma teoria realística da produção dos universais. Para tanto, ele se utiliza de uma análise tomada de sua física, que explica o modo como imagines communes são formadas no corpo. Imagens estão enraizadas nas marcas (vestigia) do corpo:

Quando uma parte fluida do corpo humano é determinada, por um corpo exterior, a se chocar, um grande número de vezes, com uma parte mole, a parte fluida modifica a superfície da parte mole e nela imprime como que traços (vestigia) do corpo exterior que a impele (idem, II postulado 5, p. 66).

Essa afirmação - a quinta da série de postulados que se referem ao corpo humano e que estão incluídos na física de Espinoza - torna-se clara se tomarmos na devida conta duas outras doutrinas fundamentais. Primeiro, Ética II p13s: "com efeito, tudo o que mostramos até agora é absolutamente geral e se aplica tanto aos homens quanto aos outros indivíduos, os quais, ainda que em graus variados são, entretanto, todos animados". Segundo, e acima de tudo, a definição de Espinoza de individuum.

Quando corpos quaisquer, de grandeza igual ou diferente, são forçados por outros corpos a se justaporem, ou se, numa outra hipótese, eles se movem, seja com o mesmo grau, seja com graus diferentes de velocidade, de maneira a transmitirem seu movimento uns aos outros segundo uma proporção definida, diremos que esses corpos estão unidos entre si e que, juntos, compõem um só corpo ou indivíduo, que se distingue dos outros por essa união de corpos (idem, II p13 Dfn, p. 64).

Nessas passagens, não é assumida nenhuma perspectiva antropocêntrica. Ao invés disso, a definição de corpo tem um sentido cosmológico, na qual, para seguir a lógica inerente à física de Espinoza, o melhor seria incluir todos os corpos que são capazes de afetar outros corpos e de serem afetados por eles. Para colocar de forma diferente, seria melhor incluir todos os corpos que são capazes de imprimir marcas (vestigia) em outros corpos, e de serem eles próprios marcados ${ }^{7}$. Evidentemente, o corpo humano tem um modo particular e excepcionalmente rico de traçar e ser traçado, e, por conseguinte, de imaginar, uma característica que Espinoza atribui à sua comparativa complexidade. Mas essa não é uma razão suficiente para negar que outros corpos possuam o poder de imaginar. A experiência comum confirma que os postulados da física de Espinoza

7 Para a discussão sobre esse aspecto da física, ver VINCIGUERRA, 2005, p. 121-37. 
(em especial o quinto) se referem ao menos a todos os corpos que costumamos considerar como animados (embora, deva-se dizer, ele não estabeleça nenhuma distinção entre animado e inanimado). Por conseguinte, desde que as condições físicas exigidas pelo Postulado $V$ sejam atendidas, o poder de ser marcado por outros corpos e o poder de marcar outros corpos devem ser reconhecidos como um poder de todos os modos corpóreos.

Além disso, o poder de significar e dar sentido por meio de marcas e signos fora e dentro do corpo não pode ser limitado às mentes dos seres humanos. A capacidade dos homens de dar sentido às coisas não é um império dentro do império da natureza. Podemos admitir, com Espinoza, que a natureza humana tende, erroneamente, a projetar nas coisas e nos eventos uma causa final, gerando, assim, uma compreensão distorcida da ordem causal. Mas isso não implica que as próprias coisas não possuam sentido, como defensores de uma visão moderna e niilista tendem a reivindicar. Se nossa imaginação precisa de marcas ou signos (isto é, algumas afecções vindas do mundo exterior) para funcionar, segue-se que não somos nem a origem e nem os autores dos sentidos que a imaginação gera. Ao invés disso, somos seus intérpretes.

Há uma tendência de se atribuir a teoria da imaginação de Espinoza exclusivamente aos seres humanos porque, geralmente, ela é considerada dentro do quadro tradicional da teoria das faculdades da mente. No entanto, está longe de ser evidente que Espinoza teria aceitado esse modelo epistemológico. Contra a tradição filosófica ocidental, ele se recusa a ver os seres humanos como substâncias e, ao invés disso, deduz uma concepção diferente de natureza de suas premissas ontológica, física e cosmológica. Seus três gêneros do conhecimento não se referem a três faculdades humanas diferentes; em vez disso, eles são três maneiras pelas quais Deus conhece sua própria natureza, modificada como é por modos finitos e infinitos, alguns deles humanos. Assim, ao invés de ser um fenômeno distintamente humano, o conhecimento que emerge da imaginação pertence, em diferentes graus, a todos os indivíduos, desde que eles respondam às definições de individuum e vestigia dadas na física de Espinoza.

Para ler Espinoza de um modo mais interessante, precisamos, portanto, nos afastar de um ponto de vista antropocêntrico e adotar uma nova perspectiva, na qual a imaginação humana é considerada como uma espécie particular de interpretação das afecções físicas. Marcas tornam-se signos tão logo são interpretadas. Mas isso também deve ser verdade para outros seres. Não seria chocante, então, falar sobre a imaginação de um girassol, mesmo se assumirmos que uma tal imaginação seria relativamente pouco desenvolvida em comparação com a humana. Sob essas condições, girassóis, assim como o homem ou outros seres, podem ser considerados como autômatos semióticos, movidos e se movendo por meio das ações das marcas.

Uma tal amplitude na capacidade de marcar e ser marcado dá uma dimensão cosmológica à doutrina de Espinoza. Isso transforma sua abordagem da imaginação, considerada como um conhecimento que fazemos derivar dos signos. Somos corpos que 
imaginam porque, como os outros tipos de corpos, participamos do processo semiótico da natureza. Dessa forma, a teoria da imaginação encontra seu fundamento físico na noção de vestigia. Vale ressaltar que a noção de vestigium não é definida especificamente por Espinoza, mas é, antes, construída a partir das noções comuns que ele usa para caracterizar a extensão - motus, individuum, mollitia e fluiditas. Assim, poderíamos considerar os vestigia dos corpos como uma noção comum secundária de res extensa.

Como esta análise nos permite apreciar, a definição de imagem dada por Espinoza reside na essência física da marca causada pelos movimentos dos corpos. As marcas, é claro, e, consequentemente, as imagens, são propriedades do corpo. Elas são afecções corpóreas, efeitos de movimento. Como tal, elas pertencem, como vimos, ao atributo da extensão. Assim, de modo a não violar o princípio do assim chamado paralelismo entre mente e corpo, é importante notar que as representações ou significados das coisas são compostos de ideias de imagens e não das próprias imagens. Estritamente falando, a potência da imaginação, como uma potência de produzir sentido, é uma virtude da mente, mesmo se essa potência é compensada pela força do corpo.

\section{A cadeia de imagens e o término do sentido}

Esse ponto nos leva a considerar um outro problema. Como a imaginação funciona? O que envolve, exatamente, imaginar? Na Ética II p17, Espinoza responde com muita clareza tal questão. Ele afirma que imaginar é produzir encadeamentos de imagens que seguem a ordem das afecções do corpo. Essa ordem, resumida pelas leis da física espinozana, não difere de um indivíduo a outro; mas o encadeamento determinado de imagens que ocorre em um corpo qualquer obviamente diferirá das cadeias que ocorrem em outros corpos. Como Espinoza explica na Ética,

Por exemplo, um romano passará imediatamente do pensamento da palavra pomum para o pensamento de uma fruta, a qual não tem qualquer semelhança com o som assim articulado, nem qualquer coisa de comum com ele a não ser que o corpo desse homem foi, muitas vezes, afetado por essas duas coisas, isto é, esse homem ouviu, muitas vezes, a palavra pomum, ao mesmo tempo em que via essa fruta. E, assim, cada um passará de um pensamento a outro, dependendo de como o hábito (consuetudo) tiver ordenado, em seu corpo, as imagens das coisas. Com efeito, um soldado, por exemplo, ao ver os rastros (vestigia) de um cavalo sobre a areia, passará imediatamente do pensamento do cavalo para o pensamento do cavaleiro e, depois, para o pensamento da guerra, etc. Já um agricultor passará do pensamento do cavalo para o pensamento do arado, do campo, etc. E, assim, cada um, dependendo de como se habituou a unir e a concatenar (jungere \& concatenare) as imagens das coisas, passará de um certo pensamento a este ou àquele outro (idem, II p18s, p. 70). 
Nessa passagem, há muitos aspectos notáveis. Primeiro, é surpreendente que não haja nenhuma distinção entre signos linguísticos e signos naturais, como as marcas deixadas por um cavalo na areia. Para Espinoza, esses dois fenômenos são, evidentemente, parte de um único problema filosófico. Uma marca na areia e o som de uma voz, considerados do ponto de vista de seu sentido, operam do mesmo modo. Ambos são imaginações, o que propicia uma ampla teoria do sentido, potencialmente aplicável a imagens de todos os tipos.

No entanto, esse não é o aspecto mais importante de II p18s. Há ainda um ponto mais relevante, como Espinoza parece indicar, o de que o sentido de uma imagem não é dado por uma imagem isolada, mas apenas por uma concatenatio, uma interconexão ou cadeia de imagens. ${ }^{8}$ Como resultado, o sonus articulatus ou o pomum ficam sem sentido até serem conectados com uma outra imagem. Imaginar é, portanto, conectar imagens ou - dito diferentemente - dar sentido às coisas pela conexão de imagens. Ademais, dado que as cadeias de imagens são sempre particulares, igualmente o serão os sentidos das imaginações. Todas as cadeias são particulares. O som articulado pomum faz sentido para um romano que compreende latim; para um chinês, contudo, esse som interromperia o encadeamento de sentido e produziria uma forma de surpresa, que Espinoza nomeia admiratio. Admiratio pode ser considerada, então, como uma súbita interrupção do encadeamento de imagens, de tal modo a não fazer mais sentido. ${ }^{9}$

Está claro, pois, que não há imaginação sem intérpretes. A palavra pomum não significa nada se não for interpretada por um romano. Uma marca na areia, em si mesma, não tem nenhum sentido enquanto não houver um intérprete sobre o qual ela tenha um efeito particular. Em princípio, isso deve ser verdade não só para intérpretes humanos, tais como soldados ou fazendeiros, mas também para outros indivíduos (animais, vegetais, minerais) capazes de desempenhar o papel de intérpretes (o problema filosófico reside no fato de poder limitar ou não a cadeia de intérpretes), como poderia ser o caso de uma formiga escalando a pegada deixada na areia por um cavalo. Para a formiga, a marca poderia significar algo distinto, talvez apenas o esforço exercido em seu corpo ao tentar superar o obstáculo. Sendo assim, a imaginação é uma intepretação cósmica dos signos, e o panpsiquismo espinozano tende para um tipo muito especial de pansemioticismo. ${ }^{10}$

Já que o encadeamento de imagens é sempre específico para cada intérprete, as leis de sua interconexão (concatenatio) devem ser encontradas no hábito (consuetudo) do intérprete. A conformação dos hábitos de um indivíduo é o que Espinoza chama de constitutio, dispositio e, algumas vezes, de ingenium. Toda imagem, tão logo faça sentido, é produto de uma interpretação que ocorre no corpo do intérprete, isto é, na maneira como ele conecta as imagens, em relação às quais as ideias representam os corpos externos como se estivessem presentes para ele.

8 Ver MOREAU, 1994, p. 321.

9 Sobre esse ponto particular, cf. VINCIGUERRA, 2005, p. 43-56; SÉVÉRAC, 2011, p. 11-25; para uma abordagem mais ampla e histórica, cf. VINCIGUERRA, 2012.

10 Cf. MESSERI, 1990, p. 195. 
Um terceiro aspecto notável da Ética II p18s é o fato de que Espinoza parece deixar em aberto a cadeia de imagens. Como ele afirma, "um soldado, por exemplo, ao ver os rastros de um cavalo sobre a areia, passará imediatamente do pensamento do cavalo para o pensamento do cavaleiro e, depois, para o pensamento da guerra, et cetera" (idem, II p18s, p. 70).

De certo modo, não há fim para um encadeamento de imagens. A semiose, como uma expressão da natureza dos corpos afetados, é infinita. Como vimos, entretanto, isso não implica que a conexão entre imagens não seja governada por leis. Ao escutar o som pomum, um romano pensará na fruta e procederá desse pensamento para outro. Caso esteja com fome, a fruta significará algo para comer; caso seja um vendedor de fruta, significará dinheiro; caso seja um cristão, significará pecado, etc. Podemos aplicar considerações similares ao soldado, ao fazendeiro e, de tal feita, a todos os indivíduos envolvidos em semioses. Podemos concluir daí que o fim pelo qual o encadeamento de sentidos opera é o próprio apetite, de cuja natureza decorre tudo aquilo que contribui para a preservação do indivíduo. Para colocar a questão como o faz Espinoza em Ética IV d7 (per finem, cujus causa aliquid facimus, appetitum intelligo), podemos dizer que o hábito do apetite é o objetivo pragmático do sentido.

Uma imagem, portanto, opera como um signo, cujo sentido final é uma ação, um hábito, um modo de vida. ${ }^{11}$ Espinoza elabora essa linha de pensamento em Ética II p40s, onde desenvolve sua teoria da imagem comum ou universal das coisas, que chama de communes imagines. Aqui, novamente, Espinoza dá uma definição genética do que a tradição filosófica chamou de universais.

Por se formarem, simultaneamente, no corpo humano, ao mesmo tempo tantas imagens, por exemplo, de homens, que elas superam a capacidade de imaginar, não inteiramente, é verdade, mas o suficiente, entretanto, para que a mente não possa imaginar as pequenas diferenças entre as coisas singulares (como, por exemplo, a cor, o tamanho, etc., de cada uma), nem o seu número exato, mas apenas aquele algo em que todos, enquanto o corpo é por ele afetado, estão em concordância, pois foi por esse algo que o corpo, por intermédio de cada indivíduo, foi mais vezes afetado. E é este algo, ou seja, aquilo em que todos estão em concordância, que a mente exprime pelo nome de homem, e que ela predica de uma infinidade de coisas singulares (idem, II p40s, p. 80-81).

É preciso notar que estas imagens comuns e as ideias que lhes correspondem não são formadas da mesma maneira por todos. Variam de indivíduo para indivíduo, a depender das coisas particulares que afetaram o corpo, da frequência com que o corpo foi afetado e, sendo assim, das coisas que a mente imagina ou recorda mais facilmente.

11 Poderíamos dizer, com Peirce, que parece estar muito próximo de Espinoza neste ponto, que o signo é algo que, sob certo aspecto ou modo, representa algo para alguém; para uma comparação entre os dois pensadores, cf. NESHER, 1994, p. 546-75; VINCIGUERRA, 2001, p. 249-67. 
Por exemplo, os que frequentemente consideram com admiração a estatura dos homens compreenderão, pelo nome de homem, um animal de estatura ereta; os que estão acostumados a considerar um outro aspecto formarão dos homens outra imagem comum, por exemplo, que é um animal que ri, que é bípede e sem penas, que é um animal racional. E assim, cada um, de acordo com a disposição de seu corpo, formará imagens universais das outras coisas (idem, II p40s, p. 81).

Essas imagens universais das coisas são signos, que indicam a existência de uma lei que governa a maneira como elas são recordadas. Por um lado, elas permanecem particulares porque são diferentes para todos; por outro lado, elas servem como universais, chegando em última instância aos termos transcendentais. Como antes, entretanto, esses signos respondem às análises que construímos. O signo é feito de imagens, as imagens são feitas de traços, e os traços pressupõem o que poderíamos chamar de um certo grau de traçabilidade para todos os corpos.

\section{Traçabilidade: uma hipótese sobre o Facies Totius Universi}

O corpo não é uma substância, mas um modo, um indivíduo. Como tal, ele inclui cada modificação sinestésica constituída por todas as maneiras pelas quais um corpo afeta outros corpos e é afetado por eles. Essa passividade/atividade pode ser definida como sua traçabilidade. A traçabilidade do corpo, ou seja, todas as maneiras pelas quais ele é capaz de traçar e ser traçado, deve corresponder, por conseguinte, à sua memória. Não seria inapropriado falar de uma espécie de scriptura e ver o corpo como um campo de práticas de inscrição e de escrita feitas de signos deixados por outros corpos e suas interpretações. A memória penetra tão profundamente na essência do corpo que se torna parte de sua identidade individual. E se, como dissemos, o corpo não é nada mais do que a extensão de suas práticas corpóreas, parece-nos, agora, que essas práticas são o verdadeiro exercício da memória.

A esse respeito, é interessante notar que, ao invés de definir os limites da identidade individual, Espinoza lança mão do exemplo de um certo poeta espanhol que esqueceu de suas próprias fabulas \& tragedias (idem, IV, p39s, p. 183). É certamente significativo que Espinoza ilustre sua concepção de corpo vivo com as práticas da linguagem e da escrita. Ao fazer isso, ele é capaz de efetivamente demonstrar o quanto a natureza de um indivíduo não é muito diferente de suas práticas de vida, que servem para individualizar sua existência e definir sua essência particular. Nesse sentido, a memória pode ser entendida como uma escrita genuína do corpo, um corpo que se inscreve a si mesmo no mundo, e ao fazer isso também é escrito.

Tendo em vista que, como vimos, não são apenas os corpos humanos que carregam os traços de suas afecções, a traçabilidade é uma propriedade de todos os indivíduos da natureza, sob a seguinte condição precisa: a de que eles sejam constituídos por 
uma relação característica do mole e do fluido, permitindo-lhes receberem as marcas de outros corpos. Por essa razão, uma teoria da traçabilidade possui, por princípio, uma dimensão cosmológica. Poderíamos sugerir aqui a seguinte hipótese. O modo infinito mediato da extensão - que Espinoza nomeia, numa expressão que ele nunca esclarece realmente, facies totius universi - coincide com a infinita traçabilidade necessária para individuar uma infinidade de corpos. O modo infinito mediato do universo acolhe a infinidade de modificações alteradas de qualquer corpo, de tal maneira que "conceberemos facilmente que a natureza inteira é um só indivíduo, cujas partes, isto é, todos os corpos, variam de infinitas maneiras, sem qualquer mudança do indivíduo inteiro" (idem, II lema 7s, p. 65). Se isso estiver correto, a noção de traçabilidade serve para esclarecer o aspecto cosmológico da ontologia de Espinoza.

A traçabilidade inerente ao corpo, em que reside seu poder de imaginação, e a infinita traçabilidade do universo constituem os dois pilares da física e da cosmologia de Espinoza, o alfa e o ômega da realidade das afecções. A traçabilidade pode ser vista como uma escritura natural, um tipo de escrita cósmica livre de todos os preconceitos da teologia, uma escrita que é totalmente natural, imanente a todas as coisas, e que não possui nenhum fim, nenhum começo, nenhum autor e nenhum sujeito. O paradigma tradicional dos dois livros - o livro da Natureza e o livro da Bíblia -, que permaneceu exercendo forte influência sobre Galileu, atinge seu ponto de plenitude e chega ao fim com Espinoza. Depois de Espinoza, a natureza não pode mais ser concebida como um livro ou um texto, pois ambos admitem um autor que lhe é externo. Ao contrário, a escritura de Espinoza é perfeitamente naturalizada em seus infinitos traços, figuras e signos. Não há nenhum outro sujeito além do mundo eterno em si mesmo, entendido como um infinito espaço de inscrição. De fato, o mundo não é mais a obra de um grande arquiteto, nem o infinito manuscrito de um autor que é o único proprietário de seu sentido. O mundo se tornou o que, então? A imanência de uma cosmo-grafia, o princípio natural de cada signo e sentido.

Para resumir a rota percorrida até agora, é possível completar a ontologia de Espinoza, e particularmente sua cosmologia, que recebeu menos atenção de seus comentadores e críticos (ver Tabela 1).

\begin{tabular}{|l|l|l|}
\hline \multicolumn{1}{|c|}{ Atributo } & \multicolumn{1}{c|}{ Pensamento } & \multicolumn{1}{c|}{ Extensão } \\
\hline Modo infinito imediato & Intelecto & Movimento \\
\hline Modo infinito mediato & Mente do Universo & $\begin{array}{l}\text { Facies totius universi } \\
\text { Infinita traçabilidade do Universo }\end{array}$ \\
\hline Modos finitos & Mentes/ideias & Corpo \\
\hline Afecção & Imaginação & $\begin{array}{l}\text { Traçabilidade dos corpos } \\
\text { vestigia, imagines, signa }\end{array}$ \\
\hline
\end{tabular}


À luz dessa análise, podemos voltar à famosa proposição 7 da segunda parte da Ética e ao seu assim chamado e, com frequência, mal compreendido paralelismo (um nome que devemos à imaginação de Leibniz, não à de Espinoza), para explorar, mais profundamente, sua perspectiva cosmológica infinita, enquanto tentamos manter seu sentido original. A ordem e a conexão de imagens são as mesmas que a ordem e a conexão de ideias; e, acrescenta-se, a ordem e a conexão de ideias são as mesmas que a ordem e a conexão das coisas. Também é possível dar um sentido renovado ao primeiro teorema da última parte da Ética: "é exatamente da mesma maneira que se ordenam e se concatenam os pensamentos e as ideias das coisas na mente que também se ordenam e se concatenam as afecções do corpo, ou seja, as imagens das coisas no corpo" (idem, V p1, p. 216). De fato, "ideias inadequadas e confusas seguem-se umas das outras com a mesma necessidade das ideias adequadas, ou seja, claras e distintas" (idem, II p36, p. 78). Na ideia de Deus, ambas expressam a mesma ordem e necessidade.

Para Descartes, os vestigia são simples poros do cérebro. Por contraste, Espinoza lhes concede um papel muito mais importante, e os considera como os fundamenta rationis. Eles contribuem fisicamente para a formação da existência particular dos indivíduos e para determinar sua potência imaginativa. A fim de avaliar a natureza e o escopo dessa alegação, precisamos, como já vimos, evitar restringir a imaginação aos seres humanos. Uma vez que a imaginação é um fenômeno cósmico, não deveríamos ficar surpresos por falar sobre a imaginação de uma formiga ou de um girassol. Visto por esse prisma, o panteísmo espinozano torna-se um panpsiquismo, e tende em direção a um pansemioticismo. Desse ponto de vista, o pensamento de Espinoza se assemelha ao de algumas tradições com as quais ele estava familiarizado, tais como o estoicismo e o calvinismo, e a alguns trabalhos que ele não chegou a conhecer, como os de Vico e Peirce.

A noção de vestigium deve ser considerada como o minimum de uma modificação corporal. Sendo assim, não é nada além do aspecto físico de uma inferência. Se as ideias representam e significam do ponto de vista do atributo pensamento, as imagens, suportadas por vestigia, carregam os sentidos do ponto de vista do atributo extensão. Isso implica algo simples, mas de considerável peso filosófico: o sentido não se origina nos humanos. Ao invés de criar o sentido, os indivíduos humanos o modificam. As mentes humanas, em conjunto com seu poder de encontrar o sentido, não são um império dentro de um império, mas estão sempre inscritas no atributo pensamento, tanto quanto seus corpos estão inscritos no atributo extensão. É isso que chamamos de realismo.

Voltemos agora ao Tractatus Theologico-Politicus. Um dos principais objetivos teóricos desse trabalho é demonstrar que a revelação profética é uma forma para ser recebida pela imaginação do profeta. O profeta é o intérprete das revelações de Deus (é assim que Espinoza traduz a palavra nabi do hebreu). Ele compreende a mensagem divina não intelectualmente, mas pelo poder da imaginação, isto é, percebendo imagens (palavras, sons, figuras, etc.) e outros signos. De acordo com Espinoza, toda revelação profética 
está adaptada à imaginação do profeta, e àquilo que podemos chamar de seu ingenium. Portanto, o sentido da revelação inclui a própria revelação e sua interpretação pelo profeta, como um encadeamento de imagens e outros signos interconectados.

Mesmo aqui e, na verdade, mais do que nunca, o sentido de um signo dependerá do indivíduo. Já que cada profeta tem sua educação, seu estilo e ingenium próprios, em uma palavra, sua maneira própria de imaginar, um único signo significará uma coisa para um profeta e outra para um outro. Como resultado, nenhum signo (incluindo aqueles que os profetas convocam para confirmar suas revelações) pode ser suficiente para garantir que alguém seja profeta. Uma doutrina e, sobretudo, boas ações são também exigidas. É impossível não ficar impressionado com a estreita relação entre Ética II p18s, onde Espinoza se refere aos diferentes encadeamentos de ideias imaginativas que caracterizam as mentes de soldados e fazendeiros, e o Tractatus Theologico-Politicus, onde encontramos Joshua, um profeta que é um miles (soldado), e Ezequiel, um profeta que é um rusticus. Espinoza estaria pensando no profeta quando escreveu esse escólio na Ética? É possível. Pelo menos, nada na sua teoria da imaginação torna isso impossível. Quando estava escrevendo o Tractatus Theologico-Politicus, Espinoza não precisava mudar sua filosofia para nos dar uma clara explanação da profecia, tampouco forçar o verdadeiro sentido do texto para salvar sua teoria da imaginação. As duas são integralmente compatíveis. ${ }^{12}$

Isso não significa, claro, que não existam diferenças entre a imaginação de pessoas comuns e a dos profetas. Certamente, elas existem. Por exemplo, Espinoza diz que o profeta tem uma imaginação vívida incomum. Mas essa diferença não é suficiente para transformar de forma radical a natureza do conhecimento que os profetas possuem ou para diferenciá-la em espécie do conhecimento imaginativo das pessoas comuns. Não é errado afirmar que a distinção entre eles, na maioria das vezes, reside no fato pragmático de que, baseados em seus conhecimentos, os profetas reais estão inclinados a fazer o bem. Além disso, essa conclusão confirma o que já dissemos sobre o objetivo pragmático do sentido. Para saber que um profeta é um verdadeiro profeta precisamos de um signo, uma doutrina e, acima de tudo, que o profeta seja reconhecido como agente de boas ações.

No início da segunda parte de Wahrheit und Method, Gadamer apresenta Espinoza como um dos pais da moderna tradição hermenêutica. Não há dúvidas de que Espinoza contribuiu para a formulação de regras racionais para interpretar um documento ou texto de um ponto de vista filológico e histórico, incluindo a Bíblia. Essa é uma de suas grandes realizações e contribuições para a ciência dos textos. Ao mesmo tempo, entretanto, ele fez muito mais. Ele concebeu a imaginação ela mesma como um processo de interpretação de signos, como uma semiosis natural, universal e interminável na qual todos os indivíduos enquanto modos participam, cada um de acordo com sua maneira de ser particular, sendo traçados e marcados por outros corpos.

12 Mais do que isso, os dois textos, a segunda parte da Ética e os capítulos I e ll do Tractatus, baseiam-se na mesma doutrina e foram, provavelmente, escritos na mesma época - em torno de 1665. 
Lorenzo Vinciguerra é professor na Universidade de Reims, França. É também professor na EHESS de Paris.

lorenzo.vinciguerra@libertysurf.fr.

Tradução de Rogério da Costa e André Fogliano (PUC-SP).

\section{Referências}

CURLEY, E. Experience in Spinoza's Theory of Knowledge. In: M. Grene (ed.), Spinoza: A Collection of Critical Essays. Notre Dame, IA: University of Notre Dame Press: Anchor Books, 1973.

FABBRI, P. La svolta semiotica. Bari: Laterza, 1998.

LAUX, H. Imagination et religion chez Spinoza: la potentia dans I'histoire. Paris: Vrin, 1993.

MESSERI, M. L'epistemologia di Spinoza: saggio sui corpi e le menti. Milano: Il Saggiatore, 1990.

MIGNINI, F. Ars imaginandi: apparenza e rapprensentazione in Spinoza. Napoli: Edizioni scientifiche italiane, 1981.

MOREAU, P.-F. Spinoza: L'expérience et l'éternité. Paris: Presses Universitaires de France, 1994.

NESHER, D. Spinoza Theory's of Truth. In: G. Hunter (ed.), Spinoza: The Enduring Questions. Toronto: University of Toronto Press, 1994.

SÉVÉRAC, P. L’admiration de la naure chez Spinoza. In: C. Ramond (ed.), Spinoza: Nature, Naturalisme, Naturation. Pessac: Presses Universitaires de Bordeaux, 2011.

SINI, C. Archivio Spinoza: La verità e la vita. Milano: Ghibli, 2015.

VINCIGUERRA, L. Image et signe entre Spinoza et Peirce: pour une lecture pragmatiste du spinozisme. In: L.Vinciguerra (ed.), Quel avenir pour Spinoza? Enquête sur les spinozismes à venir. Paris: Kimé, 2001.

Spinoza et le signe: la genèse de l'imagination. Paris: Vrin, 2005.

L'étonnement: histoire d'une passion. Philosophie, esthétique, éthique. Paris: Klincksieck, 2012.

Texto recebido em abril e aprovado em julho de 2016. 